\title{
Hyperphosphorylated tau in young and middle-aged subjects
}

\author{
Adila Elobeid · Hilkka Soininen · Irina Alafuzoff
}

Received: 14 September 2011/Revised: 16 October 2011/Accepted: 17 October 2011/Published online: 11 December 2011

(C) The Author(s) 2011. This article is published with open access at Springerlink.com

\begin{abstract}
The brain tissue obtained from ninety-five cognitively unimpaired subjects, with ages ranging from 22 to 50 years upon death, were immunohistochemically assessed for neurodegenerative changes, i.e., hyperphosphorylated tau $(\mathrm{HP} \tau)$ and $\beta$-amyloid $(\mathrm{A} \beta)$ pathology in predilection neuroanatomical areas. $\mathrm{HP} \tau$ pathology was observed in the transentorhinal cortex and/or the locus coeruleus (LC) in $33 \%$ of the subjects, without any obvious risk factors known to alter the microtubule-associated protein. $\mathrm{HP} \tau$ pathology was noted in the LC in 25 out of 83 subjects (30\%), lacking concomitant cortical A $\beta$ or transentorhinal HP $\tau$ pathology. This observation was present even when assessing only one routine section of $7 \mu \mathrm{m}$ thickness. The recent suggestion of prion-like propagation of neurodegeneration and the finding of neurodegeneration being quite common in middle-aged persons is alarming. It is noteworthy, however, that a substantial number of neurologically unimpaired subjects
\end{abstract}

\footnotetext{
A. Elobeid · I. Alafuzoff $(\bowtie)$

Department of Immunology, Genetics and Pathology, Rudbeck

Laboratory, Uppsala University/Uppsala University Hospital,

Dag Hammarskjölds väg 20, 75185 Uppsala, Sweden

e-mail: irina.alafuzoff@ipg.uu.se

H. Soininen · I. Alafuzoff

Department of Neurology, Institute of Clinical Medicine, University of Eastern Finland, P.O. Box 1627,

70211 Kuopio, Finland

H. Soininen

Department of Neurology, Kuopio University Hospital, P.O. Box 1777, 70211 Kuopio, Finland

I. Alafuzoff

Department of Clinical Pathology, Uppsala University

Hospital, SE-75185 Uppsala, Sweden
}

even at a very old age display only sparse to modest extent of neurodegenerative pathology. Thus, only a subset of subjects with neurodegenerative changes early in life seem to progress to a symptomatic disease with ageing. This observation brings forth the notion that other, yet unknown modifying factors influence the progression of degeneration that leads to a symptomatic disorder. The known association between alterations in the LC and mood disorders, and the finding of the LC being frequently affected with $\operatorname{HP} \tau$ pathology suggest that clinicopathological studies on young subjects both with or without mood disorders are warranted.

Keywords Locus coeruleus - Hyperphosphorylated tau · Immunohistochemistry · Post-mortem study ·

Middle-aged · Cognitively unimpaired

\section{Introduction}

Hyperphosphorylation of microtubule-associated protein tau is observed in primary and secondary tauopathies [22] as well as in aged, unimpaired individuals [26]. Braak and Braak [5] reported that $\mathrm{HP} \tau$ is observed in Alzheimer's disease (AD), a secondary tauopathy, in a hierarchical way where the first two stages (Braak stage I and II) are characterised by alteration seen in the transentorhinal cortex. Subjects with pathology in the first two stages are cognitively unimpaired, and do not display clinical symptoms of dementia $[4,20]$. Brainstem nuclei such as the locus coeruleus (LC) were reported to be involved with $\mathrm{HP} \tau$ pathology later in the progression, starting from stage II upward. Thus, HP $\tau$ is observed in the LC in some unimpaired aged individuals (Braak stages II-III), in subjects 
with mild cognitive impairment (MCI) and in cases with AD (Braak stages IV-VI) [8, 15].

Since the launch of the Braak-AD staging strategy, the assessment of AD-related pathology is mostly carried out on sections including, hippocampus and cortex [2]. Recently, however, Braak et al. reported that $\operatorname{HP} \tau$ pathology was seen prior to entorhinal cortex in as many as 22 subjects out of 26 while assessing individuals who died under 29 years of age (age range at death from 4 to 29 years) [7]. Furthermore, other studies have reported that regions such as dorsal Raphe nucleus or occipital visual association cortex (area 18/19) are in some cases affected prior to the transentorhinal cortex [14, 23, 25].

The aim of the present study was to assess the prevalence of $\mathrm{HP} \tau$ pathology in cognitively unimpaired middle-aged subjects. Furthermore, the objective was to investigate whether the LC was involved prior to the entorhinal cortex. The assessment was carried out applying routine sampling strategy and routine immunohistochemical (IHC) techniques.

\section{Materials and methods}

Case selection

A total of 1,505 subjects underwent a clinical autopsy, including a neuropathological examination during the years 1996-2008 at the Kuopio University Hospital, Finland. Ninety-five subjects fulfilled the selection criteria delineated for this study. First, the subjects should not have displayed cognitive impairment while alive, secondly the subjects' age at death should not exceed 50 years, and finally, all subjects with infectious disease in the brain or having primary or secondary brain tumours were excluded. Demographics of the material are summarised in Table 1.

Apolipoprotein E (APOE) genotypes were determined in a subset of cases as previously described [31].
Neuropathological assessment

According to the standard dissection protocol used in Kuopio University Hospital, the brains were weighed and then immersed for at least 1 week in $10 \%$ buffered formalin solution and thereafter, cut into $1 \mathrm{~cm}$ coronal slices. Macroscopically detectable lesions were noted. Brain specimens were taken from 16 routinely sampled brain regions: 1, frontal (Brodmann 9); 2, temporal (Brodmann 22); 3, gyrus cinguli; 4, parietal (Brodmann 39); 5, pre- and postcentral gyrus; 6, occipital cortices; 7, anterior hippocampal formation; 8, posterior hippocampal formation; 9, striatum; 10, basal forebrain including the amygdaloid complex; 11, thalamus; 12, midbrain including substantia nigra; 13, pons including LC; 14, medulla; 15, vermis and 16, cerebellar cortex. All sections were stained with hematoxylin-eosin (HE). Cerebrovascular lesions seen in the HE stained sections were classified as previously described to acute, subacute, chronic or mixed (Table 2) [1].

\section{Immunohistochemistry}

Seven micrometer thick sections were cut from formalin fixed, paraffin embedded tissue. The sections were deparaffinised, rehydrated in graded alcohol series. Details regarding staining and the specific antibody applied are summarised in Table 3. For detection, the power vision poly HPR-IHC detection kit was used with Romulin-3amino-9-ethylcarbazol (AEC) chromogen. It was determined whether $\beta$ Amyloid (A $\beta$ ) immunoreactivity (IR) was present or absent in the cortical sections (frontal, temporal and parietal cortices). Braak $\operatorname{HP} \tau$ stage was given as described previously by assessing distribution of $\operatorname{HP} \tau$ in hippocampal sections (Table 2). In the section taken at the level of pons, including LC, HP $\tau$-IR pretangles, neurites and tangles were searched for under light microscopy at $\times 40$ magnification and noted as being present or absent. Digital images were taken using an Olympus BX46 microscope equipped with an Olympus BX46 microscope

Table 1 Description of the 95 included cases

\begin{tabular}{|c|c|c|c|c|c|c|c|c|c|}
\hline \multirow{2}{*}{$\begin{array}{l}\text { Age groups } \\
\text { Age at death (years) }\end{array}$} & \multirow[t]{2}{*}{$n$} & \multicolumn{2}{|c|}{ Gender } & \multicolumn{6}{|c|}{ Primary cause of death } \\
\hline & & M & $\mathrm{F}$ & $\begin{array}{l}\text { Cerebral } \\
\text { infarct }\end{array}$ & $\begin{array}{l}\text { Circulatory } \\
\text { failure }\end{array}$ & $\begin{array}{l}\text { Neoplasia, } \\
\text { not brain }\end{array}$ & Infection & $\begin{array}{l}\text { Alcohol intoxication } \\
\text { and hepatic failure }\end{array}$ & Not available \\
\hline $20-29$ & 6 & 2 & 4 & 3 & 1 & 1 & 1 & 0 & 0 \\
\hline $30-39$ & 14 & 8 & 6 & 9 & 0 & 2 & 3 & 0 & 0 \\
\hline $40-49$ & 63 & 38 & 25 & 28 & 17 & 5 & 7 & 5 & 1 \\
\hline $50-59$ & 12 & 7 & 5 & 6 & 3 & 2 & 0 & 0 & 1 \\
\hline All & 95 & 55 & 40 & 46 & 21 & 10 & 11 & 5 & 2 \\
\hline
\end{tabular}

$n$ number of cases, $M$ male, $F$ female 
Table 2 Neuropathological observations in the 95 included cases

\begin{tabular}{|c|c|c|c|c|c|c|c|c|c|c|c|c|c|}
\hline \multirow[t]{2}{*}{$\begin{array}{l}\text { Age groups } \\
\text { Age at death } \\
\text { (years) }\end{array}$} & \multirow[t]{2}{*}{$n$} & \multirow[t]{2}{*}{$\begin{array}{l}\text { Brain weight } \\
\text { grams } \\
(\text { mean } \pm \mathrm{SE})\end{array}$} & \multicolumn{4}{|c|}{ Brain infarct $(n)$} & \multicolumn{3}{|c|}{$\begin{array}{l}\text { Hyperphosphorylated } \\
\tau \text { Braak stage }(n)\end{array}$} & \multicolumn{2}{|c|}{$\begin{array}{l}\beta \text {-amyloid } \\
\text { in the } \\
\text { cortex }(n)\end{array}$} & \multicolumn{2}{|c|}{$\begin{array}{l}\text { Hyperphosphorylate } \\
\tau \text { Locus coruleus }(n)\end{array}$} \\
\hline & & & $\begin{array}{l}\text { Acute/ } \\
\text { subacute }\end{array}$ & Chronic & $\begin{array}{l}\text { Acute/ } \\
\text { chronic }\end{array}$ & $\begin{array}{l}\text { All } \\
(\%)\end{array}$ & 0 & 1 & 2 & Yes & No & Yes & $\%$ \\
\hline $20-29$ & 6 & $1,405 \pm 79$ & 2 & 0 & 0 & $2(33)$ & 6 & 0 & 0 & 1 & 5 & 0 & 0 \\
\hline $30-39$ & 14 & $1,550 \pm 46$ & 8 & 0 & 2 & $10(71)$ & 14 & 0 & 0 & 0 & 14 & 2 & 14 \\
\hline $40-49$ & 63 & $1,482 \pm 19$ & 26 & 4 & 4 & $34(54)$ & 57 & 5 & 1 & 6 & 57 & 21 & 33 \\
\hline $50-59$ & 12 & $1,438 \pm 33$ & 4 & 1 & 2 & $7(58)$ & 12 & 0 & 0 & 0 & 12 & 5 & 42 \\
\hline All & 95 & $1,482 \pm 19$ & 40 & 5 & 8 & $53(56)$ & 89 & 5 & 1 & 7 & 88 & 28 & 29 \\
\hline
\end{tabular}

$n$ number of cases

Table 3 Immunohistochemistry

\begin{tabular}{llllll}
\hline Antibody & Code and source & Clone & Pretreatment & Dilution & Chromogen \\
\hline Hyperphosphorylated $\tau$ & Thermoscientific MN 1020 & AT8 & None & $1: 500$ & Romulin AEC \\
A $\beta$ & Dako, M0872 & $6 \mathrm{~F} / 3 \mathrm{D}$ & $80 \%$ formic acid, 6 h & $1: 100$ & Vector Red \\
A $\beta 40$ & BioSource, 44-348 & Polyclonal & $80 \%$ formic acid, 6 h & $1: 1,000$ & Vector Red \\
A $\beta 42$ & BioSource, 44-344 & Polyclonal & 80\% formic acid, 6 h & $1: 1,000$ & Vector Red \\
\hline
\end{tabular}

digital camera system (Olympus Optical Co., Ltd., Tokyo, Japan).

\section{Results}

The gender distribution of the included cases was quite even (40 females, 55 males) (Table 1). The most common primary cause of death was cerebral infarct (48\%) and the most common type of infarct was acute (Table 2). Seven out of 95 subjects (7\%) displayed $A \beta$ aggregates in the cortical sections whereas 31 out of 95 subjects (33\%) displayed HP $\tau$ pathology in some of the assessed regions. In six out of 95 subjects (6\%) lacking $\mathrm{HP} \tau, \mathrm{A} \beta$ pathology was seen in the cortex. Furthermore, in 30 subjects (32\%) lacking $\mathrm{A} \beta, \mathrm{HP} \tau$ pathology was seen in the entorhinal cortex or LC. In 28 out of 95 subjects (29\%), HP $\tau$-IR lesions were seen in the LC and HP $\tau$-IR increased with age (Tables 2, 4). All three types of lesions, i.e. pretangles, neurites, tangles, were seen in 8 subjects (Table 4; Fig. 1). In six subjects only pretangles were observed, in two others only neurites, and in two other subjects, only tangles were observed. In 3 of these 28 subjects with HP $\tau$ in the LC, $\mathrm{HP} \tau$ pathology was also observed in the entorhinal cortex to a limited extent. Concomitant cortical A $\beta$-IR and $\mathrm{HP} \tau$ IR were observed in one of these 28 subjects.

In 15 subjects (48\%) with $\mathrm{HP} \tau$ pathology, a concomitant cerebral vascular lesion was noted (Table 4); an incidence somewhat lower when compared with the 59\% that was observed in the 64 subjects lacking $\operatorname{HP} \tau$ pathology. In 3 of the 31 subjects with $\mathrm{HP} \tau$ pathology, the cerebrovascular lesions were extra-axial (aneuryms), in five an acute/subacute ischemic, in one acute/subacute hemorrhagic and in the remaining six subjects, chronic or mixed infarcts were observed. In two out of 7 subjects with $A \beta$, concomitant cerebral vascular lesions were observed (acute hemorrhagic and acute ischemic infarct) and in one case with both $\mathrm{A} \beta$ and $\mathrm{HP} \tau$, an acute hemorrhagic infarct was detected. There was no association between the type of cerebrovascular lesions and observation of HP $\tau$ pathology.

\section{Discussion}

As indicated above, 31 out of 95 (33\%) unimpaired middleaged subjects, ranging from 22 to 50 years of age at death, manifested HP $\tau$ pathology in one or both of the assessed regions, i.e. the transentorhinal cortex and the $\mathrm{LC}$, during assessments of routine diagnostic sections. Moreover, in 25 subjects out of 89 (28\%) lacking HP $\tau$ pathology in the transentorhinal cortex, HP $\tau$ pathology was seen solely in the LC. Thus, our results are, in principle, in agreement with Braak et al. [7] who recently reported the LC, frequently being affected with $\mathrm{HP} \tau$ pathology even in very young subjects. They reported that in as many as 22 out of $26(85 \%)$ young subjects lacking $\operatorname{HP} \tau$ pathology in the transentorhinal cortex, some $\mathrm{HP} \tau$ pathology was seen in the LC. This percentage of $85 \%$, in subjects ranging from 4 to 
Table 4 Details regarding pathology in the 31 subjects with hyperphosphorylated $\tau$ in entorhinal cortex and/or locus coeruleus

\begin{tabular}{|c|c|c|c|c|c|c|c|c|c|c|}
\hline \multirow[t]{3}{*}{ Case } & \multirow{3}{*}{$\begin{array}{l}\text { Age at } \\
\text { death }\end{array}$} & \multirow[t]{3}{*}{ Gender } & \multirow{3}{*}{$\begin{array}{l}\text { APOE } \\
\hat{\varepsilon} / \hat{k}\end{array}$} & \multirow{3}{*}{$\begin{array}{l}\text { Cause of } \\
\text { death }\end{array}$} & \multirow{3}{*}{$\begin{array}{l}\text { Cerebral infarct age of } \\
\text { lesion }^{\#}\end{array}$} & \multirow{3}{*}{$\begin{array}{l}\beta \text {-amyloid in the } \\
\text { cortex }\end{array}$} & \multicolumn{4}{|c|}{ Hyperphosphorylated $\tau$} \\
\hline & & & & & & & \multirow{2}{*}{$\begin{array}{l}\text { Braak } \\
\text { stage }\end{array}$} & \multicolumn{3}{|c|}{ Locus coeruleus } \\
\hline & & & & & & & & Pretangles & Neurites & Tangles \\
\hline 1 & 38 & M & na & 1 & Acute & - & - & + & + & - \\
\hline 2 & 39 & $\mathrm{~F}$ & na & 3 & Acute/chronic & - & - & + & - & - \\
\hline 3 & 41 & M & $3 / 3$ & 2 & - & - & - & - & - & + \\
\hline 4 & 41 & $\mathrm{~F}$ & na & 1 & Acute (aneurysm) & - & - & - & + & - \\
\hline 5 & 42 & $\mathrm{~F}$ & na & 4 & - & - & I & - & - & - \\
\hline 6 & 42 & M & na & 2 & Subacute & - & - & + & + & - \\
\hline 7 & 42 & $\mathrm{~F}$ & $2 / 3$ & 4 & Acute & - & - & + & - & - \\
\hline 8 & 43 & $\mathrm{~F}$ & na & 2 & - & - & - & + & - & + \\
\hline 9 & 44 & M & na & 1 & Acute(aneurysm) & - & I & - & - & - \\
\hline 10 & 44 & M & $3 / 3$ & 2 & - & - & - & + & - & - \\
\hline 11 & 44 & M & na & 2 & - & - & - & + & + & + \\
\hline 12 & 44 & $\mathrm{~F}$ & na & 3 & - & - & - & - & + & + \\
\hline 13 & 44 & M & na & na & - & - & I & - & + & - \\
\hline 14 & 44 & M & na & 2 & Acute & - & - & - & - & + \\
\hline 15 & 45 & $\mathrm{~F}$ & $3 / 3$ & 1 & Acute (aneurysm) & - & - & + & - & - \\
\hline 16 & 45 & $\mathrm{~F}$ & na & 1 & Subacute & - & - & + & + & + \\
\hline 17 & 45 & M & na & 1 & Acute (hemorrhagic) & Yes & II & + & + & + \\
\hline 18 & 46 & $\mathrm{~F}$ & na & 1 & Chronic & - & I & - & - & - \\
\hline 19 & 46 & M & na & 4 & - & - & - & + & + & + \\
\hline 20 & 46 & M & $3 / 3$ & 2 & - & - & - & + & - & - \\
\hline 21 & 47 & $\mathrm{~F}$ & na & 3 & - & - & - & + & + & + \\
\hline 22 & 47 & M & $3 / 3$ & 2 & Acute/chronic & - & I & - & + & + \\
\hline 23 & 49 & M & na & 3 & - & - & - & + & - & - \\
\hline 24 & 49 & $\mathrm{~F}$ & $3 / 3$ & 2 & Chronic & - & - & - & + & + \\
\hline 25 & 49 & M & $3 / 3$ & 1 & Acute/chronic & - & - & + & + & + \\
\hline 26 & 49 & M & na & 2 & - & - & - & - & + & + \\
\hline 27 & 50 & M & na & 2 & - & - & - & + & + & + \\
\hline 28 & 50 & M & $3 / 3$ & 2 & - & - & - & + & - & + \\
\hline 29 & 50 & M & $3 / 3$ & na & - & - & - & - & + & + \\
\hline 30 & 50 & M & $3 / 3$ & 1 & - & - & - & + & + & + \\
\hline 31 & 50 & $\mathrm{~F}$ & na & 2 & Acute/chronic & - & - & - & + & + \\
\hline
\end{tabular}

$F$ female, $M$ male, APOE Apolipoprotein E allele, na not available, 1 cerebral infarct, 2 circulatory failure, 3 neoplasia, 4 infection

\# Type of cerebral infarct, ischemic if not stated otherwise

29 years of age at death, was significantly higher when compared to our results of $28 \%$.

It is noteworthy that in our study the subjects were older in comparison with subjects studied by Braak and Del Tredici. Thus, one would have expected that the ageingrelated $\operatorname{HP} \tau$ pathology would have been observed even more frequently in our material, given that the age at death ranged from 22 to 50 years in our study. We noted in our material that indeed the incidence of $\operatorname{HP} \tau$ pathology in the LC increases with age, being $14 \%$ in the youngest and $42 \%$ in the oldest group. There are two significant differences when comparing our study with the study reported by
Braak and Del Tredici. The studies differ based on: (1) the methodology used while assessing HP $\tau$ pathology and (2) the sampling strategy of subjects.

Specifically, Braak and Del Tredici used $100 \mu \mathrm{m}$ thick sections in comparison with our $7 \mu \mathrm{m}$ thick sections. Consequently, cases displaying only occasional or few HP $\tau$-IR neurites might have been missed, due to us assessing sections that were 14 times thinner. Braak and Del Tredici reported that in 12 out of 26 cases, only HP $\tau$-IR neurites were observed in the LC (minimal pathology) whereas in 10 out of these 26 subjects, in addition to $\operatorname{HP} \tau$ IR neurites, IR nerve cells were also noted (moderate 

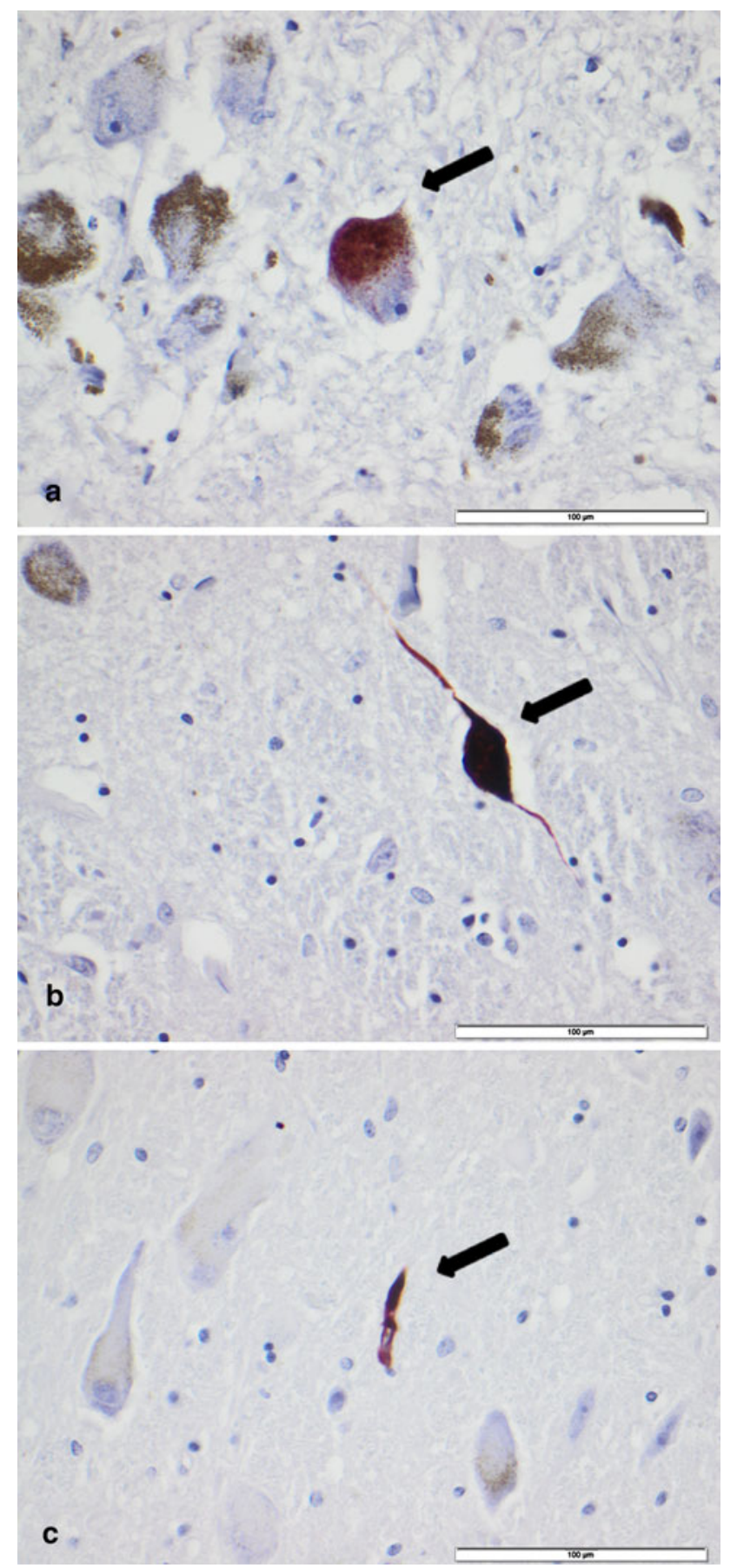

Fig. 1 AT8 immunoreactive (IR) (hyperphosphorylated $\tau$ ) lesions in a $7 \mu \mathrm{m}$ thick section of the locus coeruleus. a A 49-year-old unimpaired male subject with grainy IR material, pretangle, (arrow) in the neuronal cell body, b a 44-year-old unimpaired female with coarse AT8-IR structure, a tangle, (arrow) in the neuronal cell body and c a 41-year-old unimpaired female subject with thin AT8-IR fibres, dendrites, in the neuropil (arrow). Magnification $\times 40$. Scale bar $100 \mu \mathrm{m}$

amount of pathology). Thus, the finding of 10 subjects out of $26(38 \%)$ with IR neurites and nerve cells when assessing $100 \mu \mathrm{m}$ thick sections is more in line with our results of $28 \%$, given that we assessed sections that were 14 times thinner. While studying subjects with AD-related pathology, Busch et al. [8] reported that there is a significant difference with regard to distribution of $\mathrm{HP} \tau$ pathology in the LC. While carrying out a topographical analysis, the dorsal and medial portions of the LC were reported to be more affected when compared with the ventral and lateral portions, emphasising the importance of neuroanatomical sampling strategy [8]. This variation in topographical distribution of pathology should not have contributed to the observed differences as the sampling strategy in our study and that of Braak and Del Tredici is comparable, i.e. the tissue block assessed was obtained at the level of pontine tegmentum. Thus, the primary difference in the presence of $\operatorname{HP} \tau$ pathology in the LC is probably due to the thickness of the sections assessed, i.e. 7 versus $100 \mu \mathrm{m}$.

The selection strategy of subjects to be studied also differed. The cause of death among subjects studied by Braak and Del Tredici was quite various, including brain tumours and transplantation of organs; all diseases associated with heavy pharmaceutical treatment. Thus, in some cases hyperphosphorylation of the microtubule-associated $\tau$ protein might be due to the used pharmacological therapy. Agents such as cell cycle inhibitors, mitochondrial complex I inhibitors, anti microtubule agents as well as glucocorticoids have been reported to induce hyperphosphorylation of $\tau$ in in vivo and in vitro studies [10, 16$18,30]$. In addition, some of the subjects had suffered from head injury. An association between acute head injury and accumulation of $\operatorname{HP} \tau$ has been reported to be seen in both experimental animal studies as well as in human studies [12, 19, 32]. Our selection strategy was more stringent. Specifically, we only included subjects who died acutely without prolonged disease or heavy pharmaceutical treatment. Thus most of our subjects, 67 out of 95 , died due to an acute vascular event, i.e. cerebral or cardiac insults. Cardiovascular alterations in middle age have been suggested as being a risk factor regarding cognitive decline and dementia in later life and cardiovascular disease and AD share many common risk factors [21, 29]. However, it is noteworthy that cerebrovascular lesions were seen just as frequently, both in subjects with and also without $\mathrm{HP} \tau$ pathology. Thus, $33 \%$ of our subjects, with age ranging from 22 to 50 years at death, displayed $\operatorname{HP} \tau$ pathology in the transentorhinal cortex and/or locus coeruleus without any specific known causative reason.

Interestingly, while studying drug abusers, Anthony et al. [3] reported the LC to be affected with $\mathrm{HP} \tau$ pathology in young subjects (age at death $<30$ years). It is noteworthy that the LC was more involved than compared to the hippocampus in these young subjects; a finding in line with both our observations, and those reported by Braak and Del 
Tredici. Surprisingly, in subjects $>30$ years of age at death, the $\operatorname{HP} \tau$ pathology was reported to be more severe in the hippocampus than compared to the LC [3]. Overall, the $\mathrm{HP} \tau$ pathology increased with age; a finding in line with ours. Thus, based on the above it is obvious that the LC is indeed frequently affected with $\mathrm{HP} \tau$ pathology prior to other brain regions.

In 2004 Braak and Del Tredici stated in a commentary that the pathological process of $\mathrm{AD}$, displays a simultaneous involvement of the transentorhinal cortex, magnocellular nucleus and the LC. Furthermore, in 2011 they reported that $\mathrm{HP} \tau$ pathology in the LC is frequently seen in subjects under the age of 30 and they suggest that this pathology might be the initiation of $\mathrm{AD}$ or other tauopathies [6, 7]. In 2011, while assessing 889 cases fulfilling the Braak criteria of more than IV, Murray et al. identified three different distributional patterns, i.e., classical (75\%), limbic predominant (14\%) and hippocampal sparing (11\%). This finding suggests more than one pattern of pathological progression of $\mathrm{AD}$ [24]. 33\% of our unimpaired subjects, with age ranging from 22 to 50 years at death displayed $\mathrm{HP} \tau$ pathology in the $\mathrm{LC}$ and/or entorhinal cortex. It could be interpreted from these findings that these subjects are in a preclinical stage of a tauopathy. This interpretation would further be in line with the report of tauopathy spreading from one site to another in a transgenic mice model, indicating that tauopathy might propagate in a prion-like way and thus, all those with $\mathrm{HP} \tau$ pathology in the LC would in due time progress into a tauopathy $[9,13]$. The suggestion that young and middleaged individuals that display HP $\tau$ pathology in the LC and entorhinal cortex would progress to a symptomatic tauopathy is, however, controversial. A substantial number of neurologically unimpaired subjects even at a very old age display only sparse to modest extent of neurodegenerative pathology and only a subset of the middle-aged subjects with HP tau pathology in the LC and entorhinal cortex seem to develop a dementing disorder with aging. This observation indicates that other, yet unknown modifying mechanisms lead to the regional progression of pathology causing a symptomatic disorder.

It is noteworthy that most of our cases with $\operatorname{HP} \tau$-IR pathology in the LC did not display cortical $\mathrm{A} \beta$ aggregates. This finding is in line with results reported by Braak and Del Tredici [7]. Thus, our results and the results reported by Braak and Del Tredici are in line with the presumption that the neuronal cytoskeletal alteration is a primary lesion that might induce the extracellular deposits of $\mathrm{A} \beta$. It is also important to note, however, that Wirths et al. [33] recently reported that they were able to detect intraneuronal oligomeric assemblies of $\mathrm{N}$-terminally truncated $\mathrm{A} \beta$ peptides starting with pyroglutamate $(\mathrm{A} \beta \mathrm{pE} 3)$, not detectable with other commonly applied antibodies in an unimpaired control lacking extracellular aggregates of $\mathrm{A} \beta$. Consequently subjects, even at a very young age, should be examined for oligomeric intracellular $A \beta$ in order to assess which of the two pathologies, $\mathrm{HP} \tau$ or oligomeric $\mathrm{A} \beta$ is primarily observed.

In our study, the pathology was only seen in the transentorhinal cortex in three cases. This finding of the LC being unaffected in these three cases might be due to the methodological aspects discussed above. We only stained one section, thus a minute amount of pathology could easily have been missed. Another explanation might be related to the hypothesis proposed by Braak and Del Tredici [6], that of simultaneous involvement of the transentorhinal cortex, magnocellular nucleus and the LC with $\operatorname{HP} \tau$ pathology.

Behavioural and psychological symptoms such as depression, mood and emotional disturbances, confusion and agitation are observed in AD patients [28]. Several studies have suggested that pathological alteration in the LC and substantia nigra are probably causative regarding the depression in AD [34]. Previous assessment of the LC in subjects with mood disorders has been centred on cell count/loss. Assessment of HP $\tau$ pathology in the LC in subjects with the clinical diagnosis of pure mood disorders has not been systematically carried out to our knowledge. Association of LC pathology with depression and observation of early involvement of the LC with $\mathrm{HP} \tau$ pathology is disturbing. First, this could suggest that a tauopathy is initiated much earlier than previously even suspected. Secondly, this finding might implicate that young subjects with depression might be at risk for developing $\mathrm{AD}$ or other tauopathy in later life. Rapp et al. [27] reported that the load of pathology in subjects with AD was significantly higher in those who had suffered from a lifetime history of depression, thus, suggesting an association between these two disorders. In line with the observations above, an association between $\mathrm{AD}$ and history of early onset of depression has been reported [11]. Thus, additional postmortem studies assessing HP $\tau$ pathology in the brain stem of subjects of all ages with a diagnosis of a mood disorder are urgently needed to clarify this issue.

In summary, we conclude that $\operatorname{HP} \tau$ pathology is indeed frequently seen in the LC in unimpaired middle-aged subjects without any obvious risk factors known to alter the microtubule-associated protein. $\mathrm{HP} \tau$ pathology was noted in the LC in 25 out of 83 subjects (30\%) lacking concomitant cortical $A \beta$ or transentorhinal HP $\tau$. This observation was obtained when assessing only one section with $7 \mu \mathrm{m}$ thickness. The finding of frequent involvement of LC with HP $\tau$ pathology in early middle-aged subjects raises many questions and concerns. It is not clear whether this pathology is the primary stage of $\mathrm{AD}$ or other tauopathy or merely an insignificant alteration related to ageing. 
The suggestion of prion-like propagation of neurodegeneration would be in line with the former interpretation [13] whereas the observation of sparse extent of pathology in most aged subjects supports the latter. In most cases, HP $\tau$ was observed without concomitant $A \beta$ pathology. Recent observations have shown the presence of oligomeric $A \beta$ in aged cases without $A \beta$ aggregates. Thus, assessment of oligomeric $\mathrm{A} \beta$ in individuals with sparse $\mathrm{HP} \tau$ pathology should urgently be carried out. The association between the LC and mood disorders raises the question of whether some subjects with a mood disorder are at risk of developing a tauopathy. Clinicopathological studies on young subjects and particularly those with mood disorders are thus urgently needed.

Acknowledgments We thank the medical laboratory technologist Tarja Kauppinen, Mrs. Merja Fali, Mr. Heikki Luukkonen, Monica Sternesjö and Mr. Hannu Tiainen for their skilful technical assistance. We thank Meena Strömqvist for proofreading the manuscript. This study has been authorised by the Ethics Committee of Kuopio University Hospital and the Finnish National Authority for Medicolegal Affairs. This study has been supported by Ahfad University for Women, Khartoum, Sudan and the local ALF grants at Uppsala University Hospital.

Conflict of interest The authors report no conflicts of interest.

Open Access This article is distributed under the terms of the Creative Commons Attribution Noncommercial License which permits any noncommercial use, distribution, and reproduction in any medium, provided the original author(s) and source are credited.

\section{References}

1. Aho L, Jolkkonen J, Alafuzoff I (2006) $\beta$-amyloid aggregation in human brains with cerebrovascular lesions. Stroke 37:2940-2945

2. Alafuzoff I, Arzberger T, Al-Sarraj S et al (2008) Staging of neurofibrillary pathology in Alzheimer's disease: a study of Brain Net Europe consortium. Brain Pathol 18:484-496

3. Anthony IC, Norrby KE, Dingwall T et al (2010) Predisposition to accelerated Alzheimer-related changes in the brains of human immunodeficiency virus negative opiate abusers. Brain 133:3685-3698

4. Bancher C, Braak H, Fischer P, Jellinger KA (1993) Neuropathological staging of Alzheimer lesions and intellectual status in Alzheimer's and Parkinson's disease. Neurosci Lett 162: 179-182

5. Braak H, Braak E (1991) Neuropathological staging of Alzheimer-related changes. Acta Neuropathol 82:239-259

6. Braak H, Del Tredici K (2004) Alzheimer's disease: intraneuronal alterations precede insoluble amyloid- $\beta$ formation. Neurobiol Aging 25:713-718

7. Braak H, Del Tredici K (2011) The pathological process underlying Alzheimer's disease in individuals under 30. Acta Neuropathol 121:171-181

8. Busch C, Bohl J, Ohm TG (1997) Spatial, temporal and numeric analysis of Alzheimer changes in the nucleus coeruleus. Neurobiol Aging 18:401-406

9. Clavaguera F, Bolmont T, Crowther RA et al (2009) Transmission and spreading of tauopathy in transgenic mouse brain. Nat Cell Boil 11:909-913
10. Conejero-Goldberg C, Townsend K, Davies P (2008) Effect of cell cycle inhibitors on tau phosphorylation in N2aTau3R cells. J Mol Neurosci 35:143-150

11. Geerlings MI, den Heijer T, Koudstaal PJ, Hofman A, Breteler MM (2008) History of depression, depressive symptoms, and medial temporal lobe atrophy and the risk of Alzheimer disease. Neurology 70:1258-1264

12. Genis L, Chen Y, Shohami E, Michaelson DM (2000) Tau hyperphophorylation in apolipoprotein E-deficient and control mice after closed head injury. J Neurosci Res 60:559-564

13. Goedert M, Clavaguera F, Tolnay M (2010) The propagation of prion-like protein inclusions in neurodegenerative diseases. Trends Neurosci 33:317-325

14. Grinberg LT, Rüb U, Ferretti REL et al (2009) The dorsal Raphe nucleus shows phospho-tau neurofibrillary changes before the transentorhinal region in Alzheimer's disease. A precocious onset? Neuropathol Appl Neurobiol 35:406-416

15. Grudzien A, Shaw P, Weintraub S, Bigio E, Mash DC, Mesulam MM (2007) Locus coeruleus neurofibrillary degeneration in aging, mild cognitive impairment and early Alzheimer's disease. Neurobiol Aging 28:327-335

16. Guise S, Braguer D, Remacle-Bonnet M, Pommier G, Briand C (1999) Tau protein is involved in the apoptotic process induced by anti-microtubule agents on neuroblastoma cells. Apoptosis 4:47-58

17. Guise S, Braguer D, Carles G, Delacourte A, Briand C (2001) Hyperphosphorylation of tau is mediated by ERK activation during anticancer drug-induced apoptosis in neuroblastoma cells. J Neurosci Res 63:257-267

18. Höglinger GU, Lannuzel A, Khondiker ME et al (2005) The mitochondrial complex I inhibitor rotenone triggers a cerebral tauopathy. J Neurochem 95:930-939

19. Ikonomovic MD, Uryu K, Abrahamson EE et al (2004) Alzheimer's pathology in human temporal cortex surgically excised after severe brain injury. Exp Neurol 190:192-203

20. Jellinger K, Braak H, Braak E, Fischer P (1991) Alzheimer lesions in the entorhinal region and isocortex in Parkinson's and Alzheimer's disease. Ann NY Acad Sci 640:203-209

21. Launer LJ (2007) Next steps in Alzheimer's disease research: interaction between epidemiology and basic science. Curr Alzheimer Res 4:141-143

22. Lee VM-Y, Goedert M, Trojanowski JQ (2001) Neurodegenerative tauopathies. Ann Rev Neurosci 24:1121-1159

23. Mckee AC, Au R, Cabral HJ et al (2006) Visual association pathology in preclinical Alzheimer disease. J Neuropathol Exp Neurol 65:621-630

24. Murray ME, Graff-Radford NR, Ross OA, Petersen RC, Duara R, Dickson DW (2011) Neuropathologically defined subtypes of Alzheimer's disease with distinct clinical characteristics: a retrospective study. Lancet Neurol 10:785-796

25. Pikkarainen M, Kauppinen T, Alafuzoff I (2009) Hyperphosphorylated tau in the occipital cortex in aged nondemented subjects. J Neuropathol Exp Neurol 68:653-660

26. Price JL, Morris JC (1999) Tangles and plaques in nondemented aging and preclinical Alzheimer disease. Ann Neurol 45:358-368

27. Rapp MA, Schnaider-Beeri M, Grossman HT et al (2006) Increased hippocampal plaques and tangles in patients with Alzheimer disease with a lifetime history of major depression. Arch Gen Psychiatry 63:161-167

28. Simic G, Stanict G, Mladinov M, Jovanov-Milosevic N, Kostovic I, Hof PR (2009) Does Alzheimer's disease begin in the brain stem? Neuropathol Appl Neurobiol 35:532-554

29. Skoog I, Nilsson L, Persson G et al (1996) A15-year longitudinal study of blood pressure and dementia. Lancet 347:11411145 
30. Sotiropoulos I, Catania C, Pinto LG et al (2011) Stress acts cumulatively to precipitate Alzheimer's disease-like tau pathology and cognitive deficits. J Neurosci 31:7840-7847

31. Tsukamoto K, Watanabe T, Matsushima T et al (1993) Determination by PCR-RFLP of APOE genotype in a Japanese population. J Lab Clin Med 121:598-602

32. Uryu K, Chen X, Martinez D et al (2007) Multiple proteins implicated in neurodegenerative diseases accumulate in axons after brain trauma in humans. Exp Neurol 208:185-192
33. Wirths O, Erck C, Martens $\mathrm{H}$ et al (2010) Identification of low molecular weight pyroglutamate $\mathrm{A} \beta$ oligomers in Alzheimer disease. A novel tool for therapy and diagnosis. J Biol Chem 285:41517-41524

34. Zubenko GS, Moossy J (1988) Major depression in primary dementia. Clinical and neuropathologic correlates. Arch Neurol 45:1182-1186 